\title{
Review: The compositional variation of the rumen microbiome and its effect on host performance and methane emission
}

\author{
I. Mizrahi ${ }^{1}$ and E. Jami ${ }^{2+}$ \\ ${ }^{1}$ Department of Life Sciences, The National Institute for Biotechnology in the Negev, Ben-Gurion University of the Negev, Beer-Sheva, Israel; ${ }^{2}$ Department of \\ Ruminant Sciences, Agricultural Research Organization - the Volcani Center, 68 HaMaccabim Road, P.O.B 15159, Rishon LeZion 7505101, Israel
}

(Received 18 January 2018; Accepted 6 July 2018; First published online 24 August 2018)

The rumen microbiome has the important task of supplying ruminants with most of their dietary requirements and is responsible for up to $90 \%$ of their metabolic needs. This tremendous feat is possible due to the large diversity of microorganisms in the rumen. The rumen is considered one of the most diverse ecosystems on the planet in terms of species diversity and functional richness. From the moment the feed is ingested, it enters a vast cascade in which specialized microorganisms degrade specific components of the feed turning them into molecules, which in turn are utilized as anabolic precursors and energy sources for the animal. The output of this degradation process not only affects the animal, but also has an extensive impact on the environment. Some of the byproducts that are emitted as waste from this process, such as methane, act as greenhouse gases which greatly contribute to global warming. Recent technological advances developed to study this community enabled a larger overview of its vast taxonomic and functional diversity, thus leading to a better understanding of its ecology and function. This deeper understanding of the forces affecting the microbiome includes the forces that shape composition, the variation among animals, the stability of its key components, the processes of succession on a short- and long-time scales such as primary colonization and diurnal oscillations. These collective understandings have helped to provide insights into the potential effects that these forces have on the outputs observed from the animal itself. Over the recent years, there has been a growing body of evidence demonstrating the link between the microbiome and its effect on productivity of the host animals and the environment, which has placed rumen microbiome studies in the forefront of animal agricultural research. In this review, we focus on the natural variations in community composition, which are not the results of different management or feed but rather intrinsic features of animals. We characterize the rumen microbiome, its potential impact on its host as well as the barriers in implementing the current knowledge to modulate the microbiome and point toward potential avenues to overcome these hurdles.

Keywords: rumen microbiome, feed efficiency, methanogens, acrylate pathway, microbial colonization

\section{Implications}

The improvement of feed efficiency and, through it, product yield in cattle remains one of the most coveted goals in animal agriculture. Until now, this feat was accomplished by selective breeding, improvements in management and feed composition. Although ruminants are completely dependent on their microbiome, only recently has a link been established between the animals' physiological traits, such as energy harvest efficiency and methane emission, and its resident microbial taxa composition. Increased understanding of the rumen microbiome and its effect on animal traits may lead to novel strategies aimed at steering this community toward an improved host phenotype for increased agricultural productivity and sustainability.

\footnotetext{
${ }^{\dagger}$ E-mail: elie@volcani.agri.gov.il
}

\section{Introduction}

Ruminant herbivores have an evolved digestive system that allows absorption and digestion of large amounts of plant material as an energy source. This capability is of enormous significance to mankind, as ruminants essentially convert the energy stored in plant biomass to digestible food products (Bergman, 1990). Harnessing this process to mankind's benefit has been proposed as a driving force behind human social evolution and a decisive factor in human community fitness (Diamond, 1997).

This crucial ability to digest the plant material resides in the first compartment of the digestive tract of ruminants, termed the rumen, in which anaerobic degradation of the ingested feed occurs. Upon consumption, the feed is packed in the first two compartments of the digestive system of the cows, collectively called the reticulorumen. The feed is 
partially digested and then regurgitated and chewed again in order to increase the surface area of the feed available for further degradation by the resident microorganisms (Van Soest, 1994).

The rumen is inhabited by a dense and highly diverse microbial community, consisting of bacteria, archaea, protozoa and fungi. They are responsible for the fermentation and degradation of plant fibers which result in the conversion of plant material into digestible compounds, such as volatile fatty acids (VFA), and serve as the main energy source for the animal (Bergman, 1990). In addition, the microbes themselves are subsequently digested in the abomasum and serve as a major protein source in ruminants (Kay, 1969). Hence, the rumen microbiome is an integral part of the ruminant digestive system, essential to the animals' early development, well-being and physiology.

Other gastrointestinal microbiomes, such as those found in humans, have only recently seen an increased interest in microbiome research, outside the context of illness and infection. In contrast, the rumen microbiome was recognized already during the early days of microbiology research as a central component of the animals' well-being and physiology and the environment. Until recently, the study of complex microbial communities relied mostly on cultivation dependent methods, which allowed for an appreciation of the wide array of functions performed by the microbial community in the rumen despite the limited ability to cultivate most of the rumen microbial diversity (Wallace et al., 2017). This is likely due to the observed functional redundancy of the key functions established in the rumen, in which similar metabolic tasks are performed by a large number of species (Taxis et al., 2015; Weimer, 2015).

Still, with novel molecular techniques arising, this paradigm has shifted toward a more general attempt at surveying the overall phylogenetic and functional diversity of the rumen microbiome, and characterizing its dynamics associated with time, host animal and environmental conditions.

\section{Rumen microbiome composition}

Cultivation-independent methods, such as the wide array of sequencing technologies and microbial fingerprinting methods available today, have been commonly used during recent years to study the dynamics of the rumen microbial communities (Brulc et al., 2009; Welkie et al., 2009; Hess et al., 2011; Henderson et al., 2015; Shabat et al., 2016; Tapio et al., 2017a; Wallace et al., 2017), greatly expanding the scope of observable phylogenetic and functional diversity within the rumen.

The first of such metagenomic studies were performed on the rumen of three steers, revealing that $95 \%$ of the microbiome is composed of bacteria, between $2 \%$ and $4 \%$ archaea, and around 1\% Eukarya is composed of protozoa and fungi (Brulc et al., 2009). This study also emphasized for the first time, the vast differences observed in microbiome composition among different animals. In this study, one steer had a remarkably different microbiome composition compared with the other two steers analyzed, despite similar housing and dietary conditions and without any obvious differences in the animals' physiology (Brulc et al., 2009). Subsequent studies therefore, aimed to define the degree of variability in rumen microbiome composition and establish whether common features can still be found between all ruminants or within specific lineages, relevant to agriculture. In the most comprehensive analysis yet, the foregut microbiome of 32 ruminant and pseudoruminant species, yielding 742 samples from across the world, were analyzed. The results emphasized the shared and divergent traits in the rumen microbiome composition across a wide geographical range and animal lineages (Henderson et al., 2015). In this study, common microbial features were observed across most of the animals of different lineages sampled. The authors identified a core community of 30 bacterial taxa, with the dominant taxa being Prevotella (Bacteroidetes), Butyrivibrio and Ruminococcus (both Firmicutes), as well as unclassified Lachnospiraceae, Ruminococcaceae, Clostridiales (all Firmicutes) and Bacteroidales (Bacteroidetes) (Henderson et al., 2015). This shared presence of bacterial taxa across different foregut animal lineages suggests a longstanding relationship throughout evolution, hinting toward their key role in rumen metabolism and function (Shade and Handelsman, 2012). Ruminococcus, Butyrivibrio and Fibrobacter harbor the main known cellulolytic species, and the Prevotella genus, though non-cellulolytic, encompasses a wide array of species with different substrate degradation capabilities (Accetto and Avguštin, 2015). Within the cattle lineage, Jami and Mizrahi (2012a) identified 32 genera, recurrent in 16 cows, with Prevotella accounting for up to $72 \%$ of the bacterial population in the rumen, and hundreds of species-level operational taxonomic units (OTUs) belonging to this genus, strengthening the observed dominance of this genus in cattle (Stevenson and Weimer, 2007; Jami and Mizrahi, 2012b). Prevotella is most commonly associated with plant degradation and is not limited to ruminants. Studies on human societies living in rural areas, where the diet is mainly plant based, revealed a microbiome that is highly enriched in Prevotella (De Filippo et al., 2010). The full scope of functions within this genus is still relatively unknown because only a limited number of Prevotella species have so far been cultured. A recent study compared the genomes of 39 isolated species of Prevotella from different environments and concluded that carbohydrate-acting enzymes and polysaccharideutilization loci are highly heterogeneous within this genus (Accetto and Avguštin, 2015). Genomes from rumen isolates were mainly oriented to plant cell wall and storage polysaccharides degradation (Accetto and Avguštin, 2015). However, this is only the tip of the iceberg, as the number of Prevotella species that reside solely in the rumen are thought to reach the hundreds (Kim et al., 2011; Jami and Mizrahi, 2012a).

Similarly to the bacterial population, a core community of rumen methanogens can also be found, with the 
Methanobrevibacter consistently identified as the most abundant and ubiquitous genus across all animal species and geographical regions sampled (Morgavi et al., 2010; Henderson et al., 2015). Most of the methanogens in the rumen are hydrogenotrophic, using the hydrogen $\left(\mathrm{H}_{2}\right)$ produced through bacterial fermentation to reduce carbon dioxide $\left(\mathrm{CO}_{2}\right)$ into methane. This function is crucial for maintaining the directionality of the rumen metabolism, as the methanogens serve as an electron sink to decrease the partial pressure of $\mathrm{H}_{2}$ in the rumen, which, at high concentrations, inhibits bacterial fermentation (Morgavi et al., 2010). Other methanogenesis pathways can be found in the rumen of adult animals such as the methylotrophic used by the newly defined Methanomassiliicoccaceae family (Paul et al., 2012; lino et al., 2013; Oren and Garrity, 2015; Nkamga and Drancourt, 2016), and the less prevalent acetoclastic pathways used by members of the Methanosarcinales order (Lambie et al., 2015; Patra et al., 2017).

Despite their observed importance, the eukaryotic components of the rumen microbiome remain considerably underexplored. Researchers pointed out this knowledge gap, which also exists for most studied environments, where eukaryotic microorganisms are found to be ubiquitous yet are mostly overlooked (Caron et al., 2009).

The rumen eukaryotic community is composed of ciliate protozoa and fungi (Brulc et al., 2009). Protozoa are comparatively large single-celled eukaryotic microorganisms $(10$ to $>100 \mu \mathrm{m})$, and despite being smaller in richness compared with bacteria and archaea, estimated at $10^{5}$ to $10^{6} \mathrm{cell} / \mathrm{s} / \mathrm{ml}$ rumen fluid (Sylvester et al., 2004; Abubakr et al., 2013), account for a large proportion of the microbial biomass in the rumen, estimated to reach up to $50 \%$ (Williams and Coleman, 2012). In addition, a recent study comparing the quantification of the protozoa $18 \mathrm{~S}$ at the DNA and RNA level, revealed that while $18 \mathrm{~S}$ accounts for $<1 \%$ of the total microbial community at the DNA level, they account for $13 \%$ of the ribosomal RNA (rRNA) expressed, suggesting that this group is highly active in the rumen (Comtet-Marre et al., 2017).

Protozoa are not considered essential for animal survival, but are found to exert a large effect on the rumen ecosystem and host animal physiological characteristics (Yáñez-Ruiz et al., 2007; Mosoni et al., 2011; Newbold et al., 2015). A recent meta-analysis of multiple experiments in which ruminants underwent defaunation, a process of depleting the rumen of their protozoal components, revealed a broad effect on the ruminant physiology ranging from protein supply availability to methane emission, the latter decreasing by an average of $11 \%$ in defaunated animals (Newbold et al., 2015). The same group found that the holotrich protozoa contain a high density of endosymbiotic methanogens and may play a proportionally greater role in methanogenesis (Belanche et al., 2014 and 2015). These results emphasize the importance of studying the protozoal community and their relationship with the prokaryotic components of the rumen such as the methanogens (Belanche et al., 2014). When comparing the protozoal community with prokaryotic species in the rumen, Henderson et al. (2015) showed a higher degree of individuality both between and within foregut animal lineages, with a lower similarity both between geographically separated cohort and within specific cohorts than the ones seen in prokaryotic populations. De Menezes et al. (2011) made a similar observation which shows a strong individuality of the protozoa community between cows, overriding the effects of diet changes, despite being still observable in the bacterial and archaeal community. This lower similarity and individuality of the protozoa population suggests a more stochastic ecological mode of acquisition more dependent on random sampling from the environment and dispersal limitations, rather than strong selection within the rumen environment (Costello et al., 2012).

Anaerobic fungi also constitute an integral part of the microbiome and were shown to contribute to plant cell wall digestion. Specifically, fungi are thought to play a central role in the colonization and disruption of lignocellulolytic tissues which enable greater accessibility to fiber for bacteria (Akin and Borneman, 1990; Liggenstoffer et al., 2010; Mizrahi, 2013). All known fungi in the gut of herbivores belong to the Neocallimasticaceae family.

Like ciliates, anaerobic fungi remain largely underexplored, in terms of their diversity in ruminants and other mammalian guts. Currently, the largest study assessing the fungal diversity in the gut of herbivores (not limited to ruminant species) showed the limited knowledge in fungal diversity, with almost $40 \%$ of the sequences obtained from sequencing not belonging to any previously described genus and yielding eight newly identified, phylogenetically distinct anaerobic fungal lineages (Liggenstoffer et al., 2010). This emphasizes the limited knowledge of this important lineage and the ubiquitous nature of fungi in many gut environments. The difficulty in assessing taxonomic affiliation for fungi stems from the fact that the commonly used rRNA marker is limited in its phylogenetic information for fungi (Monard et al., 2013). Thus, the most commonly used marker to identify the phylogenetic affiliation of fungal species is the internal transcribed spacer 1 (ITS1) (Edwards et al., 2017). Phylogenetic identification is further complicated by the fact that this sequence is highly variable, making phylogenetic assignment difficult (Korabecna, 2007; Koetschan et al., 2014). To overcome this issue, the additional use of predicted secondary structure of the ITS1 region was shown to improve the ability to classify the fungal taxa using high-throughput sequencing (Koetschan et al., 2014). The improvement in classification of fungi in the rumen thus enabled the recent assessment of their composition and dynamics across different animals and diets (Ishaq et al., 2017; Tapio et al., 2017a).

\section{Microbial composition across different rumen habitats}

Adding to the complexity in the characterization of the rumen microbiome is the observation that different habitats exist within the rumen itself. Most research focuses on the comparative analysis between the liquid phase associated 
microbiome and the fiber-adherent microbial community, with a recent increased focus on the epithelium-associated microbial community (Henderson et al., 2013; Jewell et al., 2015; Deusch et al., 2017). The recent studies differentiating between the different microenvironments agree that the microbial composition in each of these microenvironments differs from one another and has distinct responses to various treatments and diets can be observed (Jewell et al., 2015; Deusch et al., 2017). A recent study assessing the differences between the ruminal fractions showed that the fiber-adherent and liquid-associated fractions harbor similar taxa, but they differ in relative proportion; whereas, the epithelium-associated microbial community harbors taxa unique to this environment (Deusch et al., 2017). The fiberadherent microbiome is characterized by a higher proportion of taxa associated with fiber degradation, such as Ruminococcaceae and Fibrobacter (Deusch et al., 2017; Vaidya et al., 2018), whereas the liquid phase is characterized by an enrichment of members of the Prevotellaceae family, capable to utilize a broad range of soluble substrates (Deusch et al., 2017; Vaidya et al., 2018). The epithelial community is characterized by taxa associated with urea hydrolysis and several aerobic taxa not found in the fiber-adherent and liquid-associated microbial community, the latter suggested to be involved in oxygen scavenging (Deusch et al., 2017). Similar to the bacterial population, the same study observed significant differences in the methanogenic population within the epithelial community harboring a higher methanogens/bacteria ratio and a higher proportion of species associated with the Methanobrevibacter genus (Deusch et al., 2017). These results emphasize the importance of differentiating between the different microbial subpopulations in the rumen in light of the scientific question being asked. Thus, exclusively relying on the liquid fraction of the rumen, as is commonly performed in these types of studies, might not capture the overall microbial diversity or the changes occurring following changes in management or diet.

\section{Compositional variation across individual animals}

Although common compositional features can be observed across different foregut animal lineages, and even more so within specific lineages such as cattle, large differences still exist between different animals of similar lineages and under similar management conditions. Li et al. (2009), using denaturing gradient gel electrophoresis (DGGE) fingerprinting analysis, revealed that there was a much lower similarity between samples taken from different host animals compared with the high similarity observed between samples taken from different regions within the rumen of the same animal (cranial, caudal, dorsal, ventral and central), and the stability across different sampling time points within the same cow. In a study using automated ribosomal intergenic spacer analysis to examine the changes in ruminal bacterial communities during the feeding cycle, similar observations were made which emphasize both the stability of the rumen microbial community when established within a cow and the large differences in composition between different cows
(Welkie et al., 2009). Similarly, Jami and Mizrahi (2012a), using the Bray-Curtis index, which takes into account both identity and abundance of the bacterial taxa, demonstrated that the average pairwise similarity between cows was 0.51 in 16 lactating cows under similar housing conditions and diet (Jami and Mizrahi, 2012a). This observation is not limited to bacteria and similar inter variation within the same host species can be seen in the other microbial domains inhabiting the rumen as well (Zhou et al., 2010; Henderson et al., 2015). Thus, there is ample evidence of inter-animal variations, even under similar conditions, and a high degree of individuality in terms of microbiome composition in the rumen.

\section{Microbiome impact on animal physiology}

\section{Feed efficiency and production}

In ruminants, fermentation products of rumen microbial activity - mainly VFA - serve as a major source of energy for the animal (Bergman, 1990). It is thus tempting to speculate that the observed inter-animal variations in microbial composition might be linked to the animals' physiological parameters of efficiency and energy loss of their individual hosts.

The potential effects of microbiome composition on animal physiology, with emphasis on performance and methane emission, have been investigated in a number of studies (Table 1). By examining microbial differences between efficient and inefficient cows, using DGGE, a connection between VFA composition, rumen bacteria and production efficiency was suggested (Hernandez-Sanabria et al., 2010). This study identified several taxa associated with parameters related to feed composition and production efficiency.

In a study assessing the potential correlation between taxa abundance of the microbiome components and physiological parameters of 15 cows, a high correlation was observed between the ratio of Firmicutes/Bacteroidetes and daily fat production in the milk (Jami et al., 2014). The difference in ratio was almost exclusively driven by the vast difference in abundance of the Prevotella genus, belonging to the Bacteroidetes phylum, which negatively correlated with milk fat yield. Additional evidence of a connection between production and the microbiome was shown in a study investigating the dynamics of the microbial population in the cow's rumen throughout two lactation periods (Jewell et al., 2015). This study also found a negative correlation between specific OTUs associated with the Prevotella genus and production efficiency. Surprisingly, these findings mirror observations from other gastrointestinal systems, in which a decreased amount of Bacteroidetes correlated with increased adiposity in the blood and tissue of mice. The authors suggest that the 'obese' microbiome has an increased capacity to harvest energy from the diet (Turnbaugh et al., 2006). However, in contrast to these findings, the same study also identified various Prevotella species associated with higher feed efficiency (Jewell et al., 2015), and an additional recent study showed that Prevotella might play a role in increasing milk production yield (Indugu et al., 2017). The large diversity mentioned within the Prevotella genus might be the cause 
Mizrahi and Jami

Table 1 Summary of experiments assessing the link between the rumen microbial community and animal physiology

\begin{tabular}{|c|c|c|c|}
\hline Animals used & Methods & Main findings & References \\
\hline Beef cattle & PCR-DGGE & Bacterial and SCFA profile linked to feed efficiency & Guan et al. (2008) \\
\hline Beef cattle & PCR-DGGE & $\begin{array}{l}\text { Higher methanogens diversity in inefficient animals. Differential prevalence } \\
\text { of Methanosphaera stadtmanae and specific Methanobrevibacter strains } \\
\text { between high and low RFI }\end{array}$ & Zhou et al. (2009) \\
\hline Beef cattle & PCR-DGGE and qPCR & $\begin{array}{l}\text { Identification of specific bacterial and archaeal OTUs associated specific } \\
\text { VFA and different RFI phenotypes in cattle under low energy diet }\end{array}$ & $\begin{array}{l}\text { Hernandez-Sanabria } \\
\text { et al. (2010) }\end{array}$ \\
\hline Beef cattle & PCR-DGGE and qPCR & $\begin{array}{l}\text { Link between bacterial profile and feed efficiency is inconsistent across } \\
\text { different diets }\end{array}$ & Carberry et al. (2012) \\
\hline Beef cattle & $\begin{array}{l}\text { Clone library and } 16 \mathrm{~S} \\
\text { sequencing }\end{array}$ & $\begin{array}{l}\text { Differential abundance of a Methanobrevibacter smithii genotypes between } \\
\text { high and low RFI animals }\end{array}$ & $\begin{array}{l}\text { Carberry et al. } \\
\text { (2014b) }\end{array}$ \\
\hline Sheep & $\begin{array}{l}\text { Metagenomic and } \\
\text { metatranscriptomic }\end{array}$ & $\begin{array}{l}\text { Higher methanogenesis-related genes expressed in high methane emitting } \\
\text { sheep }\end{array}$ & Shi et al. (2014) \\
\hline Dairy cattle & 165 amplicon sequencing & $\begin{array}{l}\text { Correlations between bacterial genera and production parameters. } \\
\text { Prevotella negatively correlated with milk fat yield }\end{array}$ & Jami et al. (2014) \\
\hline Beef cattle & $16 \mathrm{~S}$ amplicon sequencing & Higher relative abundance of Prevotella in inefficient animals & McCann et al. (2014) \\
\hline Dairy cattle & 16S amplicon sequencing & $\begin{array}{l}\text { Core OTUs associated with either efficient (Prevotella spp.) or inefficient cows } \\
\text { (Prevotella, Butyrivibrio) over the course of two lactation cycles }\end{array}$ & Jewell et al. (2015) \\
\hline Steer & Metagenomics & $\begin{array}{l}\text { Methanobrevibacter and Succinivibrionaceae more abundant in high methane } \\
\text { emitting steers }\end{array}$ & Wallace et al. (2015) \\
\hline Dairy cattle & $\begin{array}{l}16 \mathrm{~S} \text { amplicon sequencing, } \\
\text { metagenomics and } \\
\text { metabolomic }\end{array}$ & $\begin{array}{l}\text { Lower bacterial diversity in efficient cows. Identification of Megasphaera } \\
\text { elsdenii and the acrylate pathway as linked to high efficiency in dairy cattle }\end{array}$ & Shabat et al. (2016) \\
\hline Sheep & Metatranscriptomics & $\begin{array}{l}\text { Putative involvement of Sharpea azabuensis and Megasphaera spp. } \\
\text { and the acrylate pathway in low methane emission phenotype }\end{array}$ & Kamke et al. (2016) \\
\hline Dairy cattle & $16 \mathrm{~S}$ amplicon sequencing & $\begin{array}{l}\text { Prevotella, S24-7 and Succinivibrionaceae lineages positively correlated } \\
\text { with milk yield }\end{array}$ & Indugu et al. (2017) \\
\hline Dairy cattle & $16 \mathrm{~S}$ amplicon sequencing & $\begin{array}{l}\text { Methanobrevibacter ruminantium and Methanobrevibacter gottschalkii } \\
\text { associated with low methane emission }\end{array}$ & $\begin{array}{l}\text { Danielsson et al. } \\
\quad(2017)\end{array}$ \\
\hline Beef cattle & Metatranscriptomics & Higher diversity of expressed metabolic pathways in inefficient cows & Li and Guan (2017) \\
\hline
\end{tabular}

DGGE = denaturing gradient gel electrophoresis; SCFA = short-chain fatty acids; RFI = residual feed intake; qPCR = quantitative PCR; OTUs = operational taxonomic units; VFA = volatile fatty acids.

for these conflicting results and its internal composition might dictate the effect of this population on its host physiology (Jami and Mizrahi, 2012a; Accetto and Avguštin, 2015; Ley, 2016). In a large cohort study, which assessed the efficiency of 146 cows along with their microbial composition, gene content and metabolic output of the rumen, Shabat et al. (2016) observed direct evidence of different microbiome composition and gene abundance between cows with differing energy harvest capabilities. Low residual feed intake (low RFl; efficient) was shown to harbor a less diverse microbiome, but also directed toward production of molecules serving as energy for the animal compared with the microbiome of the less efficient, high RFI cows. In addition, this study revealed a differential enrichment of specific taxonomic and genomic components of the microbiome between efficient and inefficient cows (Shabat et al., 2016). These results are the product of several converging observations obtained from different types of analyses. The use of $16 \mathrm{~S}$ rRNA analysis allowed to identify several taxa enriched in the rumen of efficient cows, including the lactate utilizing Megasphaera elsdenii and Coprococcus catus significantly enriched in efficient cows. The $M$. elsdenii, although found in relatively low proportion in both efficient and inefficient cows compared with other species in the rumen, could also be seen significantly enriched in the rumen of efficient cows using shotgun metagenome sequencing and read alignment to its genome. The metagenome also identified the acrylate pathway, encoded among others by the $M$. elsdenii and C. catus, as the only propionic acid pathway significantly enriched in the rumen of efficient cows. The taxonomic and genomic results were further strengthened by the metabolomic analysis, assessing the overall metabolic outputs of fermentation, in which lactate was found to be in lower abundance in the rumen of efficient cows, suggesting it to be more efficiently utilized by the microbiome. The congruence between the different methods used highlights lactate as a crucial intermediate and the acrylate pathway, significantly enriched in the rumen of efficient cows, as a contributing factor in steering metabolism toward production of VFA. On the other hand, inefficient cows exhibiting a lower abundance of this species and the mentioned genes had their metabolism directed toward increased methane production (Shabat et al., 2016). The authors proposed a model in which the microbiome composition affects the ratio of end products during fermentation. The efficient cows' microbiome was shown to steer production toward VFA through the 
intermediate product lactate, driven by the enrichment of lactate utilizing bacteria via the acrylate pathway such as M. elsdenii and C. catus (Shabat et al., 2016). In contrast, within inefficient cows, rumen metabolism was shown to be steered toward unusable end products such as methane, evidenced by the specific enrichment of the Methanobrevibacter ruminantium species and the increase in methane production.

These findings were further strengthened by another study showing the connection between the microbiome composition and the methane emission, which also observed that lactate utilization, directed toward butyrate production by, among others, Megasphaera spp., results in low methane yield in sheep (Kamke et al., 2016).

\section{Methane emission}

In parallel to the efforts carried out at understanding the role of the microbiome in energy harvest and feed efficiency, an increasing interest at linking the microbiome to the observed energy loss through methane emission has developed (Tapio et al., 2017b). Methanogenic archaea are a driving force for the rumen microbiome metabolism and serve as an electron sink for the entire ecosystem driving the directionality of the fermentation process (van Lingen et al., 2016). However, methanogenesis carries drawbacks related to both the animal's energy-harvesting efficiency and the vast impact it exerts on the environment. Methane cannot be absorbed by the host and is therefore emitted to the environment and constitutes a substantial energy loss for the animal (Johnson and Ward, 1996). Methane is also a potent greenhouse gas greatly contributing to the greenhouse effect. These drawbacks led to intensified research efforts to improve performance along with mitigating energy losses through methane.

Evidence of a connection between the methanogenic population and production efficiency was observed in a study assessing the methanogen identity and composition in efficient $v$. inefficient cows (Zhou et al., 2009). This study revealed that, while similar methanogen abundance was observed between the groups, their composition was significantly different and a higher proportion of Methanosphaera stadtmanae and Methanobrevibacter spp. strain abM4 could be observed in inefficient cows (Zhou et al., 2009). Using metatranscriptomics analysis to assess the expression levels of microbial genes in sheep classified as low and high methane emitters, Shi et al. (2014) showed increased expression of $\mathrm{CO}_{2} / \mathrm{H}_{2}$ methanogenesis pathway genes in the rumen of high methane emitting sheep.

In a recent study, metagenomics analysis showed a significantly higher prevalence of Methanobrevibacter in the rumen of high methane emitting steers (Wallace et al., 2015). This study, however, also noted differences in the microbiome beyond the methanogens themselves, with both bacterial taxa and genes differentially expressed in the rumen of high emitters compared with low emitters. The authors emphasized the higher prevalence of the Succinivibrionaceae family and related genes within the low emitting sheep. Succinivibrionaceae was also found in high abundance in studies characterizing the microbiome of the Tammar Wallaby, and was speculated to be related to their observed naturally low methane emission (Pope et al., 2011). Interestingly, a prominent Succinivibrionaceae species, Succinivibrio dextrinosolvens, is a known minor lactate producer in the rumen (O'Herrin and Kenealy, 1993). Thus, methanogenesis is a complex process that may involve not only the methanogens but also other components of the microbiome. Network analysis approaches using patterns of co-occurrence and abundance-based correlations may help uncover these connections (Layeghifard et al., 2017), and a recent study applying these approaches revealed several putative interactions between the different microbial domains in the rumen (Tapio et al., 2017a). The authors, however, pointed out that no mechanistic explanation is yet available and requires further investigation (Tapio et al., 2017a).

Wallace et al. (2015) also identified the Megasphaera genus as being significantly enriched in the rumen of low emitting cows. As mentioned, M. elsdenii was subsequently identified twice in the context of both increased efficiency and low methane emission (Kamke et al., 2016; Shabat et al., 2016). The consistency of these results suggest that lactate, and lactate-related bacterial species and genes, may represent a central intermediate pathway to the production of VFA, naturally enriched in a subset of animals, serving as an alternative to methanogenesis. This is supported by previous meta-analyses and theoretical studies suggesting VFA as alternative electron sinks to methane in the rumen (Ungerfeld, 2013 and 2015).

Interestingly, previous studies attempted to enrich the rumen of cows with $M$. elsdenii isolated from the rumen, in order to stabilize ruminal $\mathrm{pH}$ by decreasing lactate concentration and alter VFA profile toward increasing acetate and butyrate production (Zebeli et al., 2012; Weimer et al., 2015). Despite being unsuccessful in stably transplanting the bacteria and altering rumen composition, focusing on this species or other lactate utilizers may represent an interesting avenue worth pursuing for the purpose of both increased feed efficiency and methane mitigation.

\section{Potential modulation of the rumen microbiome}

Modulation of the microbiome toward a more optimized phenotype remains one of the main challenges in the field and has been attempted in numerous studies (Table 2). Prior attempts resulted in transient or no success in obtaining a stable optimized population in the mature rumen (Weimer, 2015). The rumen microbiome, although quite dissimilar between different animals, exhibits a remarkable specificity and resilience within its host (Weimer, 2015). Although these features serve as an anchor for studying the effect of different microbial makeups on the host over time (Li et al., 2009; Jewell et al., 2015), they also hinder the possibility of microbial manipulation and to follow the long-term effect of such changes. Most attempts at introducing bacteria, indigenous to the rumen, resulted in only a temporary 
Mizrahi and Jami

Table 2 List of rumen exogenous inoculation experiments and the main effects on the microbiome and animal

\begin{tabular}{|c|c|c|c|}
\hline Animals & Type of inoculum & Main findings & References \\
\hline Gnotobiotic lambs & Designed minimal bacterial consortium & $\begin{array}{l}\text { Consortium partly established until the end } \\
\text { of the experiment. Minimal microbiome } \\
\text { contributes to the health of lambs }\end{array}$ & $\begin{array}{l}\text { Mann and Stewart } \\
\text { (1974) }\end{array}$ \\
\hline Gnotobiotic lambs & $\begin{array}{l}\text { Combinations of mixed defined bacterial } \\
\text { consortium }\end{array}$ & Consortium partly established & Lysons et al. (1976) \\
\hline Gnotobiotic lambs & $\begin{array}{l}\text { Simplified undefined microbial } \\
\text { community }+ \text { Fibrobacter succinogenes and } \\
\text { protozoa }\end{array}$ & $\begin{array}{l}\text { VFA composition and animal health affected } \\
\text { by the complexity and type of inoculate }\end{array}$ & Fonty et al. (1983) \\
\hline Adult sheep & Genetically modified Prevotella ruminicola & $\begin{array}{l}\text { Inoculum below detectable levels after } 3 \mathrm{~h} \text {. } \\
\text { Suspected bacteriocin activity responsible } \\
\text { for the extinction }\end{array}$ & Attwood et al. (1988) \\
\hline Adult cows & $\begin{array}{l}\text { Antibiotic resistant Selenomonas ruminantium } \\
\text { and Mitsuokella multiacidus }\end{array}$ & $\begin{array}{l}\text { S. ruminantium persisted in the rumen after } \\
30 \text { days. Rapid extinction of } M \text {. multiacidus }\end{array}$ & Flint et al. (1989) \\
\hline Adult sheep & $\begin{array}{l}\text { Multiple dosage of antibiotic resistant isolated } \\
\text { S. ruminantium }\end{array}$ & $\begin{array}{l}\text { Transient increase of the inoculum. Undetectable } \\
\text { after } 24 \mathrm{~h}\end{array}$ & $\begin{array}{l}\text { Wallace and Walker } \\
\text { (1993) }\end{array}$ \\
\hline Adult goat & Antibiotic resistant Ruminococcus albus & Detectable after 14 days (end of experiment) & Miyagi et al. (1995) \\
\hline Gnotobiotic lambs & $\begin{array}{l}\text { Twice weekly dosing of multiple cellulolytic } \\
\text { Ruminococcus strains }\end{array}$ & Gradual extinction 3 weeks after final dosing & Krause et al. (1999) \\
\hline Adult sheep & $\begin{array}{l}\text { Recombinant Butrivibrio fibrisolvens expressing } \\
\text { Ehrlichia ruminantium xylanase gene }\end{array}$ & Rapid decline to extinction after $144 \mathrm{~h}$ in vivo & Kobayashi et al. (2001) \\
\hline Adult sheep & Dosing of multiple Ruminococcus Spp. & $\begin{array}{l}\text { Not stably established. Changes in the overall } \\
\text { microbiome and physiological parameters }\end{array}$ & Krause et al. (2001a) \\
\hline Sheep, cattle & $\begin{array}{l}\text { Recombinant } B \text {. fibrisolvens with Neocallimastix } \\
\text { patriciarum xylanase }\end{array}$ & Decline to extinction after 22 days & Krause et al. (2001b) \\
\hline Dairy cattle & $\begin{array}{l}\text { Repeated dosing of Ruminococcus } \\
\text { flavefaciens + probiotic }\end{array}$ & $\begin{array}{l}\text { Rapid decline of inoculated species regardless } \\
\text { of added probiotic }\end{array}$ & Chiquette et al. (2007) \\
\hline Dairy cattle & Total exchange of rumen fluid & $\begin{array}{l}\text { Transient change in pH and VFA profile. Rapid } \\
\text { recovery of the bacterial community to } \\
\text { pre-exchanged composition }\end{array}$ & Weimer et al. (2010) \\
\hline Reindeer & R. flavefaciens strain 8/94-32 & $\begin{array}{l}\text { Strain undetected post-dosing. Modulation } \\
\text { of the overall microbial composition }\end{array}$ & Præsteng et al. (2013) \\
\hline Dairy cattle & Multiple $M$. elsdenii strains & $\begin{array}{l}\text { M. elsdenii population reverted to baseline } \\
\text { levels after } 24 \mathrm{~h}\end{array}$ & Weimer et al. (2015) \\
\hline Beef cattle & Repeated inoculation of bison rumen fluid & $\begin{array}{l}\text { Alteration of the rumen microbiome } \\
\text { Increased protein digestibility }\end{array}$ & Ribeiro et al. (2017) \\
\hline Dairy cattle & Total exchange of rumen fluid & $\begin{array}{l}\text { Transient change in milk production and bacterial } \\
\text { community. Solid-associated community } \\
\text { reverted to pre-exchanges composition }\end{array}$ & Weimer et al. (2017) \\
\hline Beef cattle & Total exchange of rumen fluid & $\begin{array}{l}\text { Strong host individuality in response } \\
\text { to inoculation during microbiome } \\
\text { re-establishment }\end{array}$ & Zhou et al. (2018) \\
\hline
\end{tabular}

VFA = volatile fatty acids.

increase of the inoculum, followed by its decrease to extinction in a matter of days to a few weeks (Wallace and Walker, 1993; Krause et al., 2001a; Chiquette et al., 2008; Zebeli et al., 2012; Weimer et al., 2015). The microbiome is resilient to such an extent, that a recent study, which almost completely replaced the rumen fluid of one cow with the rumen fluid from another cow, showed that within just a few weeks, rumen microbiome content reverted to a content more closely resembling its original composition (Weimer et al., 2017). This stresses the fact that even the most extreme perturbation of the microbiome could not change the rumen microbial composition in a stable manner and suggests a high host specificity of the rumen microbiome composition once established. Moreover, recent studies show a connection between the individual animals' genetics and its respective microbiome, as well as heritability of some rumen microbiome components (Roehe et al., 2016; Li et al., 2016; Sasson et al., 2017). These factors might hinder successful inoculation of previously isolated microbial strains.

This challenge is not exclusive to rumen microbiome studies and can be observed in microbiome studies of other gastrointestinal systems (Kristensen et al., 2016). However, a recent study succeeded in engrafting a known endogenous species within the already established human gut. In this study, the researchers administered orally Bifidobacterium longum, a naturally residing member of the human 
microbiome. The inoculated bacterium could stably colonize the gut in a subset of inoculated humans, which exhibited an initially low abundance of this bacterium along with low levels of genes related to carbohydrate utilization (Maldonado-Gómez et al., 2016). Hence, long-term microbial modulation is possible but may require a consideration of the ecological niches taken up by the initial microbiome to assess the receptivity of the resident microbiome to the inoculated species.

The challenges in modulating the adult microbiome led scientists to assess the possibility of early intervention, at a time when the microbiome is still developing, and a higher success was achieved through dietary modulation (Abecia et al., 2013 and 2014) or direct microbial consortia inoculation of germ-free animals (Lysons et al., 1976; Fonty et al., 1983), resulting in observable long-term effects. Thus, the dynamics of initial colonization and its long-term effects on the adult microbiome may provide a potential avenue in future attempts at microbiome modulation.

\section{Rumen development and microbial colonization}

The digestive system of ruminants is unique in that it switches from a monogastric functionality (similar to non-ruminant mammals) to becoming fully functional post weaning (Van Soest, 1994).

During the first weeks of life, when the animals are still suckling milk, the rumen is not functional: the ingested milk bypasses the rumen due to a closure of the esophageal groove by reflex action (Van Soest, 1994). The proportional weight of the rumen within the digestive tract is considerably smaller, on average $25 \%$, compared with the mature rumen reaching $60 \%$ to $80 \%$ of the total digestive system (Krishnamoorthy and Moran, 2012). In addition, many of its functional attributes, such as the rumen wall villi which are involved in the absorption of nutritional components, are not yet developed (Van Soest, 1994).

Developmental changes of the rumen structure and physiology with age have been shown to be linked to the development of the rumen microbial population. The extensive host-bacteria crosstalk through their fermentation products in the form of VFA was shown to be instrumental to the development of the rumen papillae (Sander et al., 1959). This emphasizes the crucial role of the rumen microbiome has on its host development. Early research in rumen microbial colonization in calves and lambs revealed that initial colonization is done by aerobic and facultative anaerobic microbial taxa immediately after birth, which gradually decrease in abundance while being replaced by mostly anaerobic taxa (Fonty et al., 1987; Minato et al., 1992). These studies showed that some bacterial species, whose functions are associated with the mature functionality of the rumen such as cellulolytic bacteria, begin to appear immediately after birth and before weaning or exposure to plantbased feed (Fonty et al., 1987; Minato et al., 1992). More recently, culture-independent methods observed similar dynamic changes occurring in the rumen over time (Li et al.,
2012; Jami et al., 2013; Rey et al., 2013; Kumar et al., 2015; Dill-McFarland et al., 2017). These studies revealed rapid bacterial population turnover with the community found in 1-day-old calves being vastly different from that found in 3-day-old calves (Jami et al., 2013). These changes are suggested to be influenced partly by the oxygen availability during this period, as the initial community is mainly composed of aerobic and facultative anaerobes, which are quickly being supplanted by anaerobic and facultative bacteria (Fonty et al., 1987; Minato et al., 1992; Jami et al., 2013; Rey et al., 2013). These results suggest that the oxidative state of the rumen is a major driver of change in the newborn rumen community. The redox potential effect on the microbiome is not limited to the early stages of development and has also been shown to be a factor affecting the adult methanogenic community as well, with different redox potential affecting the growth of specific methanogenic species isolated from the rumen (Friedman et al., 2016). The studies on rumen colonization further revealed that bacteria associated with mature rumen function, such as cellulose and hemicellulose degradation, can already be found 1 day after birth (Fonty et al., 1987; Minato et al., 1992; Jami et al., 2013). Those include the cellulolytic bacteria Ruminococcus albus and Ruminococcus flavefaciens and members of the Prevotella genus (Jami et al., 2013). Thus, the rumen is primed immediately after birth, with functional bacteria relevant to the mature rumen. The extent of initial priming with plant degrading bacteria during colonization and how they are able to thrive before the ingestion of plant material remains unclear and warrants further investigation.

One of the major changes observed throughout rumen development consists of a shift in composition within the Bacteroidetes phylum. In the mature rumen this phylum is dominated by the genus Prevotella, which is the overall dominant genus across many ruminants (Stevenson and Weimer, 2007; Jami and Mizrahi, 2012a; Henderson et al., 2015). However, during the initial stages of development the Bacteroides is the dominant genus within Bacteroidetes and is quickly overtaken by the Prevotella within the first 2 months (Li et al., 2012; Rey et al., 2013). This drastic shift in dominance was proposed to coincide with the introduction of plant-based feed, and has been observed to occur in monogastric animals, including humans (De Filippo et al., 2010).

The rapid changes in community composition are not limited to the bacteria and can also be found in the methanogenic archaea community (Friedman et al., 2017). The establishment of methanogenic communities in the rumen of calves and lambs was shown to occur close to birth (Fonty et al., 1987; Minato et al., 1992; Skillman et al., 2004; Friedman et al., 2017), with a recent study observing that methanogens could be detected as early as 20 min after birth (Guzman et al., 2015).

Similarly to the bacterial population, the initial methanogenic population differs greatly compared with the one in mature animals (Skillman et al., 2004; Friedman et al., 2017). Comparative analysis of the order level composition of the methanogenic community of pre-weaning calves during the first 2 months after birth and mature animals showed that 
the mature rumen is composed of mostly the Methanobacteriales order and a low proportion of the newly characterized Thermoplasmata class. In contrast, within the rumen of pre-weaning calves, two additional orders could be detected: the Methanosarcinales and Methanomicrobiales (Friedman et al., 2017). These compositional differences were shown to affect the nature of methanogenesis in terms of substrate utilization prevalence. Although the mature rumen is mainly composed of hydrogenotrophic methanogens, whose metabolism is driven by the reduction of $\mathrm{CO}_{2}$ with $\mathrm{H}_{2}$ to produce methane, the young rumen seems to have a higher prevalence of other pathways to produce methane. This include the methylotrophic pathway in which several species of methanogens metabolize methanol and methylamine compounds as a substrate for methanogenesis (Thauer et al., 2008; Poulsen et al., 2013). When Friedman et al. (2017) incubated the rumen fluid of young calves and mature cows with different methanogenesis substrate, methane production in the fluid derived from young calves increased 5- to 10-fold following the addition of methylamine or methanol; whereas, $\mathrm{H}_{2}$ addition only slightly increased methane production. Although no information about methylamines' presence can be found regarding the developing rumen environment, choline, their main precursor, can be found in high abundance in milk-fed newborn calves; the availability of which may be responsible for the different methanogenesis characteristics in the young rumen (Hill and Mangan, 1964; Neill et al., 1978; Wallace, 1979; Zeisel et al., 2003; Artegoitia et al., 2014). In contrast, the mature rumen fluid responded the strongest to the addition of $\mathrm{H}_{2}$ during incubation. This suggests that environmental conditions during early stages of colonization favor alternative pathway to methane production (Friedman et al., 2017).

\section{Conclusions}

Although the main goals in animal agriculture have remained the same over the years, our approach to the major challenges revolving around them has evolved along with the deeper understanding of the tripartite relationship between the environment, the host animal and its residing microbes. The recognized role of microbes in ruminant physiology predates the modern interest of what is called today 'microbiome'; however with the advent of high-throughput technologies, new data emerge at a rapid rate, each with its own methodological setup. The aim of this review is to consolidate those results and describe the recent observations that were reproduced to some degree across different studies and conducted under different setups. The recurrence of these observations has the power to steer research more accurately and successfully toward broader agricultural applications.

Such is the case for the remarkable congruence observed in several recent studies, in which similar microbial taxa and genes linked to feed efficiency or methane emission, in cattle and sheep. Although not always converging, both phenotypes relate to energy conversion from the feed. The acrylate pathway, which converts lactate to propionate, was highly enriched in both efficient cows and low methane emitting sheep and cows. These results highlight the central role of specific microbial pathway and the associated taxa could have on improving yield and developing a more environmental friendly livestock farming.

To this day, long-term, stable attempts at modulating the rumen microbiome have proven unsuccessful due mostly to the resilience of the rumen microbiome once established. However, the recent success in stably introducing a specific bacterial species in the gut of humans suggests that targeted introduction and modulation of the microbiome is possible. Whether stable, targeted microbial inoculation can be applied in the rumen environment remains to be tested, but considering that similar ecological principles apply to the microbiome of different environment such as microbial colonization (Costello et al., 2012; Yatsunenko et al., 2012; Jami et al., 2013), this latest development may open a pathway to a more targeted approach by considering the ecological features of the resident microbiome.

Understanding the ecology of the rumen unique microbial system may open new avenues for the optimization of livestock agriculture, toward increased agricultural productivity, together with mitigation of its negative impact on the environment.

\section{Acknowledgments}

The authors thank Tanita Wein and Matthew Metzger for their helpful comments and critical reading of the manuscript.

The review was supported by grants from the Israel Science Foundation (no. 1313/13), by the European Research Council under the European Union's Horizon 2020 research and innovation program (grant agreement no. 640384), the Israeli Dairy Board foundation (no. 362-0524/25) and the Israeli Ministry of Agriculture and Rural Development (no. 362-0542).

\section{Declaration of interest}

None.

\section{Ethics statement}

All ethical standards have been met.

\section{Software and data repository resources None.}

\section{References}

Abecia L, Martín-García Al, Martínez G, Newbold CJ and Yáñez-Ruiz DR 2013. Nutritional intervention in early life to manipulate rumen microbial colonization and methane output by kid goats postweaning. Journal of Animal Science 91, 4832-4840.

Abecia L, Waddams KE, Martínez-Fernandez G, Martín-García Al, RamosMorales E, Newbold CJ and Yáñez-Ruiz DR 2014. An antimethanogenic nutritional intervention in early life of ruminants modifies ruminal colonization by archaea. Archaea 2014, 841463. 
Abubakr AR, Alimon AR, Yaakub H, Abdullah N and Ivan M 2013. Digestibility, rumen protozoa, and ruminal fermentation in goats receiving dietary palm oil by-products. Journal of the Saudi Society of Agricultural Sciences 12, 147-154. Accetto T and Avguštin G 2015. Polysaccharide utilization locus and CAZYme genome repertoires reveal diverse ecological adaptation of Prevotella species. Systematic and Applied Microbiology 38, 453-461.

Akin DE and Borneman WS 1990. Role of rumen fungi in fiber degradation. Journal of Dairy Science 73, 3023-3032.

Artegoitia VM, Middleton JL, Harte FM, Campagna SR and de Veth MJ 2014. Choline and choline metabolite patterns and associations in blood and milk during lactation in dairy cows. PloS One 9, e103412.

Attwood GT, Lockington RA, Xue GP and Brooker JD 1988. Use of a unique gene sequence as a probe to enumerate a strain of Bacteroides ruminicola introduced into the rumen. Applied and Environmental Microbiology 54, 534-539.

Belanche A, de la Fuente G and Newbold CJ 2014. Study of methanogen communities associated with different rumen protozoal populations. FEMS Microbiology Ecology 90, 663-677.

Belanche A, de la Fuente $G$ and Newbold CJ 2015. Effect of progressive inoculation of fauna-free sheep with holotrich protozoa and total-fauna on rumen fermentation, microbial diversity and methane emissions. FEMS Microbiology Ecology 91, fiu026.

Bergman EN 1990. Energy contributions of volatile fatty acids from the gastrointestinal tract in various species. Physiological Reviews 70, 567-590.

Brulc JM, Antonopoulos DA, Miller ME, Wilson MK, Yannarell AC, Dinsdale EA, Edwards RE, Frank ED, Emerson JB, Wacklin P, Coutinho PM, Henrissat B, Nelson KE and White BA 2009. Gene-centric metagenomics of the fiber-adherent bovine rumen microbiome reveals forage specific glycoside hydrolases. Proceedings of the National Academy of Sciences of the United States of America 106, 1948-1953.

Carberry CA, Kenny DA, Han S, McCabe MS and Waters SM 2012. Effect of phenotypic residual feed intake and dietary forage content on the rumen microbial community of beef cattle. Applied and environmental microbiology 78 , 4949-4958.

Carberry CA, Kenny DA, Kelly AK and Waters SM 2014a. Quantitative analysis of ruminal methanogenic microbial populations in beef cattle divergent in phenotypic residual feed intake (RFI) offered contrasting diets. Journal of Animal Science and Biotechnology 5, 41.

Carberry CA, Waters SM, Waters SM, Kenny DA and Creevey CJ 2014b. Rumen methanogenic genotypes differ in abundance according to host residual feed intake phenotype and diet type. Applied and Environmental Microbiology 80, 586-594.

Caron DA, Worden AZ, Countway PD, Demir E and Heidelberg KB 2009. Protists are microbes too: a perspective. The ISME Journal 3, 4-12.

Chiquette J, Allison MJ and Rasmussen MA 2008. Prevotella bryantii 25A used as a probiotic in early-lactation dairy cows: effect on ruminal fermentation characteristics, milk production, and milk composition. Journal of Dairy Science 91, 3536-3543.

Chiquette J, Talbot G, Markwell F, Nili N and Forster RJ 2007. Repeated ruminal dosing of Ruminococcus flavefaciens $\mathrm{NJ}$ along with a probiotic mixture in forage or concentrate-fed dairy cows: effect on ruminal fermentation, cellulolytic populations and in sacco digestibility. Canadian Journal of Animal Science 87, 237-249.

Comtet-Marre S, Parisot N, Lepercq $P$, Chaucheyras-Durand $F$, Mosoni $P$, Peyretaillade E, Bayat AR, Shingfield KJ, Peyret P and Forano E 2017. Metatranscriptomics reveals the active bacterial and eukaryotic fibrolytic communities in the rumen of dairy cow fed a mixed diet. Frontiers in Microbiology 8, 67 . Costello EK, Stagaman K, Dethlefsen L, Bohannan BJ and Relman DA 2012. The application of ecological theory toward an understanding of the human microbiome. Science 336, 1255-1262.

Danielsson R, Dicksved J, Sun L, Gonda H, Müller B, Schnürer A and Bertilsson J 2017. Methane production in dairy cows correlates with rumen methanogenic and bacterial community structure. Frontiers in Microbiology 8, 226.

De Filippo C, Cavalieri D, Di Paola M, Ramazzotti M, Poullet JB, Massart S, Collini S, Pieraccini G and Lionetti P 2010. Impact of diet in shaping gut microbiota revealed by a comparative study in children from Europe and rural Africa. Proceedings of the National Academy of Sciences of the United States of America $107,14691-14696$. de Menezes AB, Lewis E, O'Donovan M, O'Neill BF, Clipson N and Doyle EM 2011. Microbiome analysis of dairy cows fed pasture or total mixed ration diets. FEMS Microbiology Ecology 78, 256-265.

Deusch S, Camarinha-Silva A, Conrad J, Beifuss U, Rodehutscord M and Seifert J 2017. A structural and functional elucidation of the rumen microbiome influenced by various diets and microenvironments. Frontiers in Microbiology 8, 1605 .

Diamond J 1997. Guns, germs, and steel: the fates of human societies. W.W. Norton, New York, NY, USA.

Dill-McFarland KA, Breaker JD and Suen G 2017. Microbial succession in the gastrointestinal tract of dairy cows from 2 weeks to first lactation. Scientific Reports 7, 40864.

Edwards JE, Forster RJ, Callaghan TM, Dollhofer V, Dagar SS, Cheng Y, Chang J, Kittelmann S, Fliegerova K, Puniya AK, Henske JK, Gilmore SP, O'Malley MA, Griffith GW and Smidt H 2017. PCR and omics based techniques to study the diversity, ecology and biology of anaerobic fungi: insights, challenges and opportunities. Frontiers in Microbiology 8, 1657.

Flint HJ, Bisset J and Webb J 1989. Use of antibiotic resistance mutations to track strains of obligately anaerobic bacteria introduced into the rumen of sheep. The Journal of Applied Bacteriology 67, 177-183.

Fonty G, Gouet P, Jouany J-P and Senaud J 1987. Establishment of the microflora and anaerobic fungi in the rumen of lambs. Journal of General Microbiology $133,1835-1843$

Fonty G, Jouany JP, Thivend P, Gouet P and Senaud J 1983. A descriptive study of rumen digestion in meroxenic lambs according to the nature and complexity of the microflora. Reproduction, Nutrition, Development 23, 857-873.

Friedman N, Jami E and Mizrahi I 2017. Compositional and functional dynamics of the bovine rumen methanogenic community across different developmental stages. Environmental Microbiology 8, 3365-3373.

Friedman N, Shriker E, Gold B, Durman T, Zarecki R, Ruppin E and Mizrahi I 2016. Diet-induced changes of redox potential underlie compositional shifts in the rumen archaeal community. Environmental Microbiology 19, 174-184.

Guan LL, Nkrumah JD, Basarab JA and Moore SS 2008. Linkage of microbial ecology to phenotype: correlation of rumen microbial ecology to cattle's feed efficiency. FEMS Microbiology Letters 288, 85-91.

Guzman CE, Bereza-Malcolm LT, De Groef B and Franks AE 2015. Presence of selected methanogens, fibrolytic bacteria, and proteobacteria in the gastrointestinal tract of neonatal dairy calves from birth to 72 hours. PloS One 10, e0133048.

Henderson G, Cox F, Ganesh S, Jonker A, Young W, Global Rumen Census Collaborators and Janssen PH 2015. Rumen microbial community composition varies with diet and host, but a core microbiome is found across a wide geographical range. Scientific Reports 5, 14567.

Henderson G, Cox F, Kittelmann S, Miri VH, Zethof M, Noel SJ, Waghorn GC and Janssen PH 2013. Effect of DNA extraction methods and sampling techniques on the apparent structure of cow and sheep rumen microbial communities. PloS One 8, e74787.

Hernandez-Sanabria E, Guan LL, Goonewardene LA, Li M, Mujibi DF, Stothard P, Moore SS and Leon-Quintero MC 2010. Correlation of particular bacterial PCRdenaturing gradient gel electrophoresis patterns with bovine ruminal fermentation parameters and feed efficiency traits. Applied and Environmental Microbiology 76, 6338-6350.

Hess M, Sczyrba A, Egan R, Kim T-W, Chokhawala H, Schroth G, Luo S, Clark DS, Chen F, Zhang T, Mackie RI, Pennacchio LA, Tringe SG, Visel A, Woyke T, Wang Z and Rubin EM 2011. Metagenomic discovery of biomass-degrading genes and genomes from cow rumen. Science 331, 463-467.

Hill KJ and Mangan JL 1964. The formation and distribution of methylamine in the ruminant digestive tract. Biochemical Journal 93, 39-45.

lino T, Tamaki H, Tamazawa S, Ueno Y, Ohkuma M, Suzuki K-I, Igarashi Y and Haruta S 2013. Candidatus Methanogranum caenicola: a novel methanogen from the anaerobic digested sludge, and proposal of Methanomassiliicoccaceae fam. nov. and Methanomassiliicoccales ord. nov., for a methanogenic lineage of the class Thermoplasmata. Microbes and Environments/ 28, 244-250.

Indugu N, Vecchiarelli B, Baker LD, Ferguson JD, Vanamala JKP and Pitta DW 2017. Comparison of rumen bacterial communities in dairy herds of different production. BMC Microbiology 17, 190.

Ishaq SL, AlZahal O, Walker N and McBride B 2017. An investigation into rumen fungal and protozoal diversity in three rumen fractions, during high-fiber or 
Mizrahi and Jami

grain-induced sub-acute ruminal acidosis conditions, with or without active dry yeast supplementation. Frontiers in Microbiology 8, 1943.

Jami E, Israel A, Kotser A and Mizrahi I 2013. Exploring the bovine rumen bacterial community from birth to adulthood. The ISME Journal 7, 1069-1079. Jami E and Mizrahi I 2012a. Composition and similarity of bovine rumen microbiota across individual animals. PloS One 7, e33306.

Jami $\mathrm{E}$ and Mizrahi I 2012b. Similarity of the ruminal bacteria across individual lactating cows. Anaerobe 18, 338-343.

Jami E, White BA and Mizrahi I 2014. Potential role of the bovine rumen microbiome in modulating milk composition and feed efficiency. PloS One 9, e85423.

Jewell KA, McCormick CA, Odt CL, Weimer PJ and Suen G 2015. Ruminal bacterial community composition in dairy cows is dynamic over the course of two lactations and correlates with feed efficiency. Applied and Environmental Microbiology 81, 4697-4710.

Johnson DE and Ward GM 1996. Estimates of animal methane emissions. Environmental Monitoring and Assessment 42, 133-141.

Kamke J, Kittelmann S, Soni P, Li Y, Tavendale M, Ganesh S, Janssen PH, Shi W Froula J and Rubin EM 2016. Rumen metagenome and metatranscriptome analyses of low methane yield sheep reveals a Sharpea-enriched microbiome characterised by lactic acid formation and utilisation. Microbiome 4, 56.

Kay R 1969. Digestion of protein in the intestines of adult ruminants. The Proceedings of the Nutrition Society 28, 140-151.

Kim M, Morrison M and Yu Z 2011. Status of the phylogenetic diversity census of ruminal microbiomes. FEMS Microbiology Ecology 76, 49-63.

Kobayashi Y, Yamada M and Yamamoto M 2001. Survival of a recombinant rumen bacterium in the rumen of sheep. Nihon Chikusan Gakkaiho 72 344-346.

Koetschan C, Kittelmann S, Lu J, Al-Halbouni D, Jarvis GN, Müller T, Wolf M and Janssen PH 2014. Internal transcribed spacer 1 secondary structure analysis reveals a common core throughout the anaerobic fungi (Neocallimastigomycota). Plos One 9, e91928.

Korabecna M 2007. The variability in the fungal ribosomal DNA (ITS1, ITS2, and $5.8 \mathrm{~S}$ rRNA gene): its biological meaning and application in medical mycology. Communicating Current Research and Educational Topics and Trends in Applied Microbiology 2, 783-787.

Krause DO, Bunch RJ, Conlan LL, Kennedy PM, Smith WJ, Mackie RI and McSweeney CS 2001a. Repeated ruminal dosing of Ruminococcus spp. does not result in persistence, but changes in other microbial populations occur that can be measured with quantitative 16S-rRNA-based probes. Microbiology 147, 1719-1729.

Krause DO, Bunch RJ, Dalrymple BD, Gobius KS, Smith WJ, Xue GP and McSweeney CS 2001b. Expression of a modified Neocallimastix patriciarum xylanase in Butyrivibrio fibrisolvens digests more fibre but cannot effectively compete with highly fibrolytic bacteria in the rumen. Journal of Applied Microbiology 90, 388-396.

Krause DO, Smith WJ, Ryan FM, Mackie RI and McSweeney CS 1999. Use of 16SrRNA based techniques to investigate the ecological succession of microbial populations in the immature lamb rumen: tracking of a specific strain of inoculated ruminococcus and interactions with other microbial populations in vivo. Microbial Ecology 38, 365-376.

Krishnamoorthy $U$ and Moran J 2012. Rearing young ruminants on milk replacers and starter feeds. FAO Animal Production and Health, Rome, Italy.

Kristensen NB, Bryrup T, Allin KH, Nielsen T, Hansen TH and Pedersen 02016. Alterations in fecal microbiota composition by probiotic supplementation in healthy adults: a systematic review of randomized controlled trials. Genome Medicine 8, 52.

Kumar S, Indugu N, Vecchiarelli B and Pitta DW 2015. Associative patterns among anaerobic fungi, methanogenic archaea, and bacterial communities in response to changes in diet and age in the rumen of dairy cows. Frontiers in Microbiology 6, 781.

Lambie SC, Kelly WJ, Leahy SC, Li D, Reilly K, McAllister TA, Valle ER, Attwood GT and Altermann E 2015. The complete genome sequence of the rumen methanogen Methanosarcina barkeri CM1. Standards in Genomic Sciences 10, 57.

Layeghifard M, Hwang DM and Guttman DS 2017. Disentangling interactions in the microbiome: a network perspective. Trends in Microbiology 25, 217-228.
Ley RE 2016. Gut microbiota in 2015: prevotella in the gut: choose carefully. Nature Reviews. Gastroenterology \& Hepatology 13, 69-70.

Li F and Guan LL 2017. Metatranscriptomic profiling reveals linkages between the active rumen microbiome and feed efficiency in beef cattle. Applied and Environmental Microbiology 75, 6524-6533.

Li RW, Connor EE, Li C, Baldwin Vi RL and Sparks ME 2012. Characterization of the rumen microbiota of pre-ruminant calves using metagenomic tools. Environmental Microbiology 14, 129-139.

Li M, Penner GB, Hernandez-Sanabria E, Oba M and Guan LL 2009. Effects of sampling location and time, and host animal on assessment of bacterial diversity and fermentation parameters in the bovine rumen. Journal of Applied Microbiology 107, 1924-1934.

Li Z, Wright A-DG, Si H, Wang X, Qian W, Zhang Z and Li G 2016. Changes in the rumen microbiome and metabolites reveal the effect of host genetics on hybrid crosses. Environmental Microbiology Reports 8, 1016-1023.

Liggenstoffer AS, Youssef NH, Couger MB and Elshahed MS 2010. Phylogenetic diversity and community structure of anaerobic gut fungi (phylum Neocallimastigomycota) in ruminant and non-ruminant herbivores. The ISME Journal 4, 1225-1235.

Lysons RJ, Alexander TJ, Wellstead PD, Hobson PN, Mann SO and Stewart CS 1976. Defined bacterial populations in the rumens of gnotobiotic lambs. Journal of General Microbiology 94, 257-269.

Maldonado-Gómez MX, Martínez I, Bottacini F, O'Callaghan A, Ventura M, van Sinderen D, Hillmann B, Vangay P, Knights D, Hutkins RW and Walter J 2016. Stable engraftment of Bifidobacterium longum AH1206 in the human gut depends on individualized features of the resident microbiome. Cell Host \& Microbe 20, 515-526.

Mann SO and Stewart CS 1974. Establishment of a limited rumen flora in gnotobiotic lambs fed on a roughage diet. Journal of General Microbiology 84, 379-382.

McCann JC, Wiley LM, Forbes TD, Rouquette FM Jr and Tedeschi LO 2014. Relationship between the rumen microbiome and residual feed intake-efficiency of Brahman bulls stocked on bermudagrass pastures. PloS One 9, e91864.

Minato H, Otsuka M, Shirasaka S, Itabashi H and Mitsumori M 1992. Colonization of microorganisms in the rumen of young calves. The Journal of General and Applied Microbiology 38, 447-456.

Miyagi T, Kaneichi K, Aminov RI, Kobayashi Y, Sakka K, Hoshino S and Ohmiya K 1995. Enumeration of transconjugated Ruminococcus albus and its survival in the goat rumen microcosm. Applied and Environmental Microbiology 61, 2030-2032.

Mizrahi I 2013. Rumen symbioses. In The prokaryotes (ed. E Rosenberg, EF DeLong, S Lory, E Stackebrandt and F Thompson), pp. 533-544. Springer, Berlin/ Heidelberg.

Monard C, Gantner S and Stenlid J 2013. Utilizing ITS1 and ITS2 to study environmental fungal diversity using pyrosequencing. FEMS microbiology ecology $84,165-175$.

Morgavi DP, Forano E, Martin C and Newbold CJ 2010. Microbial ecosystem and methanogenesis in ruminants. Animal 4, 1024-1036.

Mosoni P, Martin C, Forano E and Morgavi DP 2011. Long-term defaunation increases the abundance of cellulolytic ruminococci and methanogens but does not affect the bacterial and methanogen diversity in the rumen of sheep. Journal of Animal Science 89, 783-791.

Neill AR, Grime DW and Dawson RM 1978. Conversion of choline methyl groups through trimethylamine into methane in the rumen. Biochemical Journal 170, 529-535.

Newbold CJ, de la Fuente G, Belanche A, Ramos-Morales E and McEwan NR 2015. The role of ciliate protozoa in the rumen. Frontiers in Microbiology $6,1313$.

Nkamga VD and Drancourt M 2016. Methanomassiliicoccaceae. In Bergey's manual of systematics of Archaea and Bacteria (ed. WB Whitman). John Wiley \& Sons Ltd, Chichester, UK. doi:10.1002/9781118960608.fbm00269.

O'Herrin SM and Kenealy WR 1993. Glucose and carbon dioxide metabolism by Succinivibrio dextrinosolvens. Applied and Environmental Microbiology 59 748-755

Oren A and Garrity GM 2015. List of new names and new combinations previously effectively, but not validly, published. International Journal of Systematic and Evolutionary Microbiology 65, 3763-3767. 
Patra A, Park T, Kim M and Yu Z 2017. Rumen methanogens and mitigation of methane emission by anti-methanogenic compounds and substances. Journal of Animal Science and Biotechnology 8, 13.

Paul K, Nonoh J0, Mikulski L and Brune A 2012. 'Methanoplasmatales,' thermoplasmatales-related archaea in termite guts and other environments, are the seventh order of methanogens. Applied and Environmental Microbiology 78, 8245-8253.

Pope PB, Smith W, Denman SE, Tringe SG, Barry K, Hugenholtz P, McSweeney CS, McHardy AC and Morrison M 2011. Isolation of Succinivibrionaceae implicated in low methane emissions from Tammar wallabies. Science 333, 646-648.

Poulsen M, Schwab C, Jensen BB, Engberg RM, Spang A, Canibe N, Højberg O, Milinovich G, Fragner L and Schleper C 2013. Methylotrophic methanogenic thermoplasmata implicated in reduced methane emissions from bovine rumen. Nature Communications 4, 1428.

Præsteng KE, Pope PB, Cann IKO, Mackie RI, Mathiesen SD, Folkow LP, Eijsink VGH and Sundset MA 2013. Probiotic dosing of Ruminococcus flavefaciens affects rumen microbiome structure and function in reindeer. Microbial Ecology 66, 840-849.

Rey M, Enjalbert F, Combes S, Cauquil L, Bouchez 0 and Monteils V 2013. Establishment of ruminal bacterial community in dairy calves from birth to weaning is sequential. Journal of Applied Microbiology 116, 245-257.

Ribeiro GO, Oss DB, He Z, Gruninger RJ, Elekwachi C, Forster RJ, Yang W, Beauchemin KA and McAllister TA 2017. Repeated inoculation of cattle rumen with bison rumen contents alters the rumen microbiome and improves nitrogen digestibility in cattle. Scientific Reports 7, 1276.

Roehe R, Dewhurst RJ, Duthie C-A, Rooke JA, McKain N, Ross DW, Hyslop JJ, Waterhouse A, Freeman TC, Watson M and Wallace RJ 2016. Bovine host genetic variation influences rumen microbial methane production with best selection criterion for low methane emitting and efficiently feed converting hosts based on metagenomic gene abundance. PLoS Genetics 12, e1005846.

Sander EG, Warner RG, Harrison HN and Loosli JK 1959. The stimulatory effect of sodium butyrate and sodium propionate on the development of rumen mucosa in the young calf. Journal of Dairy Science 42, 1600-1605.

Sasson G, Kruger Ben-Shabat S, Seroussi E, Doron-Faigenboim A, Shterzer N, Yaacoby S, Berg Miller ME, White BA, Halperin E and Mizrahi I 2017. Heritable bovine rumen bacteria are phylogenetically related and correlated with the cow's capacity to harvest energy from its feed. mBio 8, e00703-e00717.

Shabat SKB, Sasson G, Doron-Faigenboim A, Durman T, Yaacoby S, Miller MEB, White BA, Shterzer N and Mizrahi I 2016. Specific microbiome-dependent mechanisms underlie the energy harvest efficiency of ruminants. The ISME Journal 10, 2958-2972.

Shade A and Handelsman J 2012. Beyond the Venn diagram: the hunt for a core microbiome. Environmental Microbiology 14, 4-12.

Shi W, Moon CD, Leahy SC, Kang D, Froula J, Kittelmann S, Fan C, Deutsch S, Gagic D and Seedorf H 2014. Methane yield phenotypes linked to differential gene expression in the sheep rumen microbiome. Genome Research 24, 1517-1525.

Skillman LC, Evans PN, Naylor GE, Morvan B, Jarvis GN and Joblin KN 2004. 16S ribosomal DNA-directed PCR primers for ruminal methanogens and identification of methanogens colonising young lambs. Anaerobe 10, 277-285.

Stevenson DM and Weimer PJ 2007. Dominance of Prevotella and low abundance of classical ruminal bacterial species in the bovine rumen revealed by relative quantification real-time PCR. Applied Microbiology and Biotechnology 75, 165-174.

Sylvester JT, Karnati SKR, Yu Z, Morrison M and Firkins JL 2004. Development of an assay to quantify rumen ciliate protozoal biomass in cows using real-time PCR. The Journal of Nutrition 134, 3378-3384.

Tapio I, Fischer D, Blasco L, Tapio M, Wallace RJ, Bayat AR, Ventto L, Kahala M, Negussie E, Shingfield KJ and Vilkki J 2017a. Taxon abundance, diversity, co-occurrence and network analysis of the ruminal microbiota in response to dietary changes in dairy cows. PloS One 12, e0180260.

Tapio I, Snelling TJ, Strozzi F and Wallace RJ 2017b. The ruminal microbiome associated with methane emissions from ruminant livestock. Journal of Animal Science and Biotechnology 8, 7.

Taxis TM, Wolff S, Gregg SJ, Minton NO, Zhang C, Dai J, Schnabel RD, Taylor JF, Kerley MS, Pires JC, Lamberson WR and Conant GC 2015. The players may change but the game remains: network analyses of ruminal microbiomes suggest taxonomic differences mask functional similarity. Nucleic Acids Research 43, 9600-9612.

Thauer RK, Kaster A-K, Seedorf H, Buckel W and Hedderich R 2008. Methanogenic archaea: ecologically relevant differences in energy conservation. Nature Reviews. Microbiology 6, 579-591.

Turnbaugh PJ, Ley RE, Mahowald MA, Magrini V, Mardis ER and Gordon JI 2006. An obesity-associated gut microbiome with increased capacity for energy harvest. Nature 444, 1027-1031.

Ungerfeld EM 2013. A theoretical comparison between two ruminal electron sinks. Frontiers in Microbiology 4, 319.

Ungerfeld EM 2015. Shifts in metabolic hydrogen sinks in the methanogenesis-inhibited ruminal fermentation: a meta-analysis. Frontiers in Microbiology 6, 37.

Vaidya JD, van den Bogert B, Edwards JE, Boekhorst J, van Gastelen S, Saccenti $\mathrm{E}$, Plugge CM and Smidt $\mathrm{H}$ 2018. The effect of DNA extraction methods on observed microbial communities from fibrous and liquid rumen fractions of dairy cows. Frontiers in Microbiology 9, 92.

van Lingen HJ, Plugge CM, Fadel JG, Kebreab E, Bannink A and Dijkstra J 2016. Thermodynamic driving force of hydrogen on rumen microbial metabolism: a theoretical investigation. PloS One 11, e0161362.

Van Soest PJ 1994. Nutritional ecology of the ruminant. Cornell University Press, New York, NY, USA.

Wallace RJ 1979. Effect of ammonia concentration on the composition, hydrolytic activity and nitrogen metabolism of the microbial flora of the rumen. The Journal of Applied Bacteriology 47, 443-455.

Wallace RJ, Rooke JA, McKain N, Duthie C-A, Hyslop JJ, Ross DW, Waterhouse A, Watson $M$ and Roehe $R$ 2015. The rumen microbial metagenome associated with high methane production in cattle. BMC Genomics 16, 839.

Wallace RJ, Snelling TJ, McCartney CA, Tapio I and Strozzi F 2017. Application of meta-omics techniques to understand greenhouse gas emissions originating from ruminal metabolism. Genetics, Selection, Evolution 49, 9.

Wallace RJ and Walker ND 1993. Isolation and attempted introduction of sugar alcohol-utilizing bacteria in the sheep rumen. The Journal of Applied Bacteriology 74, 353-359.

Weimer PJ 2015. Redundancy, resilience, and host specificity of the ruminal microbiota: implications for engineering improved ruminal fermentations. Frontiers in Microbiology 6, 296.

Weimer PJ, Cabral LDS and Cacite F 2015. Effects of ruminal dosing of Holstein cows with Megasphaera elsdenii on milk fat production, ruminal chemistry, and bacterial strain persistence. Journal of Dairy Science 98, 8078-8092.

Weimer PJ, Cox MS, de Paula TV, Lin M, Hall MB and Suen G 2017. Transient changes in milk production efficiency and bacterial community composition resulting from near-total exchange of ruminal contents between high-and lowefficiency Holstein cows. Journal of Dairy Science 100, 7165-7182.

Weimer PJ, Stevenson DM, Mantovani HC and Man S 2010. Host specificity of the ruminal bacterial community in the dairy cow following near-total exchange of ruminal contents. Journal of Dairy Science 93, 5902-5912.

Welkie DG, Stevenson DM and Weimer PJ 2009. ARISA analysis of ruminal bacterial community dynamics in lactating dairy cows during the feeding cycle. Anaerobe 16, 94-100.

Williams AG and Coleman GS 2012. The rumen protozoa. Springer-Verlag, New York, NY, USA.

Yáñez-Ruiz DR, Williams S and Newbold CJ 2007. The effect of absence of protozoa on rumen biohydrogenation and the fatty acid composition of lamb muscle. The British Journal of Nutrition 97, 938-948.

Yatsunenko T, Rey FE, Manary MJ, Trehan I, Dominguez-Bello MG, Contreras M, Magris M, Hidalgo G, Baldassano RN, Anokhin AP, Heath AC, Warner B, Reeder J, Kuczynski J, Caporaso JG, Lozupone CA, Lauber C, Clemente JC, Knights D, Knight $R$ and Gordon JI 2012. Human gut microbiome viewed across age and geography. Nature 486, 222-227.

Zebeli Q, Terrill SJ, Mazzolari A, Dunn SM, Yang WZ and Ametaj BN 2012. Intraruminal administration of Megasphaera elsdenii modulated rumen fermentation profile in mid-lactation dairy cows. The Journal of Dairy Research 79, 16-25. Zeisel SH, Mar M-H, Howe JC and Holden JM 2003. Concentrations of cholinecontaining compounds and betaine in common foods. The Journal of Nutrition $133,1302-1307$ 
Mizrahi and Jami

Zhou MI, Hernandez-Sanabria E and Guan LL 2009. Assessment of the microbial ecology of ruminal methanogens in cattle with different feed efficiencies. Applied and Environmental Microbiology 75, 6524-6533.

Zhou M, Hernandez-Sanabria E and Guan LL 2010. Characterization of variation in rumen methanogenic communities under different dietary and host feed efficiency conditions, as determined by PCR-denaturing gradient gel electrophoresis analysis. Applied and Environmental Microbiology 76, 3776-3786.

Zhou M, Peng Y-J, Chen Y, Klinger CM, Oba M, Liu J-X and Guan LL 2018. Assessment of microbiome changes after rumen transfaunation: implications on improving feed efficiency in beef cattle. Microbiome 6, 62 . 